\title{
The distribution, abundance and habitat preferences of the Salmon-crested Cockatoo Cacatua moluccensis on Seram, Indonesia
}

\author{
STUART J. MARSDEN
}

\begin{abstract}
Summary
The Salmon-crested Cockatoo Cacatua moluccensis is endemic to the Seram island group, Maluku Province, Indonesia. An apparently considerable population decline, attributed to over-exploitation for the parrot trade, prompted CITES to ban all trade in the species in 1989. A short census was undertaken on Seram using the variable circular plot method. Cockatoo density estimates were highest in little-disturbed lowland forest and lowest in recently logged forest and in non-forested areas. Discriminant function analysis was used to describe the distribution of the species. The discriminant profile suggested that cockatoos were associated with mature lowland forest closer to rather than farther away from settlements. No conclusions are possible as to the relative importance of bird capture and habitat alteration on the population of the Salmon-crested Cockatoo, but an urgent need for further standardized censuses of cockatoo populations, and for research concerning the population dynamics of this and other traded parrot species, is stressed.
\end{abstract}

\section{Introduction}

Indonesia is rich in parrots and the Seram island group, situated in Maluku Province, holds no fewer than 11 parrot species, of which three are endemic. The Salmon-crested Cockatoo Cacatua moluccensis is endemic to this island group, being found on Seram itself, and on the smaller islands of Ambon, Haruku and Saparua (Forshaw 1989).

The native forests on Seram may have been utilized by small numbers of indigenous people for centuries, but more recently there has been larger-scale clearance of forest, especially in the lowlands. Most of Seram's coastal strip has been converted to grassland, agriculture, plantation or scrub, while since 1980 selective logging and forest clearance for agriculture and resettlement programmes have been extensive (FAO 1981, Smiet 1982). One of the few areas to escape is the Manusela National Park. This protected area covers approximately $11 \%$ of Seram's land area, and although there is a $200 \mathrm{~km}^{2}$ "enclave" in the Manusela valley which remains inhabited by indigenous people, $90 \%$ of forest within the park was reported to be "pristine" (FAO 1981). However, 26\% of the park's total area is above $1,000 \mathrm{~m}$ above sea level, and only $27 \%$ (approx. $490 \mathrm{~km}^{2}$ ) is below $500 \mathrm{~m}$ (figures from digitized 1:250,000 General Topography Map no. 5). The protection afforded to the Salmon-crested Cockatoo within the park and the response of Seram's parrots to land-use changes outside the park are very little understood. 
The hunting and capture of parrots has been practised for generations by indigenous islanders in Indonesia. Recently, the numbers caught for both the domestic and, more importantly, the international pet trade have caused major concern. Net imports of Salmon-crested Cockatoos as reported to CITES (and therefore an absolute minimum) for the period 1983 to 1988 averaged 9,571 (as processed by the World Conservation Monitoring Centre in 1991). With the available information indicating a population decline (Stresemann 1914, Smiet 1985, Inskipp et al. 1988, Bowler and Taylor 1989), a complete ban on trade in the species was implemented by CITES in 1989.

The aim of this study was to gather baseline information on the distribution and abundance of Salmon-crested Cockatoos on Seram, and to relate these data to the concurrent factors of bird capture and changes in land use.

\section{Study area and methods}

Five weeks from 19 December 1989 were spent on Seram collecting field data in the Manusela National Park, and in lowland habitats in northern Seram. The variable circular plat method (Reynolds et al. 1980) was employed to produce density estimates of bird species in the areas surveyed. The method involves recording all birds seen or heard at "stations" during a fixed time period (in this case ten minutes). The distance to each bird encounter was estimated and the birds' positions (low, mid-level, canopy or aerial) were recorded with the number of individuals in each encounter and whether birds were seen, heard or both. Each station was at a distance of a walk of ten minutes from the next station. Encounters with all parrot species were recorded (as in Milton and Marhadi 1987) on the walks between stations and on other walks where stations were not established. All bird censusing using the circular plot method was carried out between $06 \mathrm{~h} 30$ and 11 hoo and only in the absence of rain.

At each station, habitat readings were taken prior to the bird recordings. Estimates were made of distance to the ten nearest trees of diameter at breast height $>20 \mathrm{~cm}$. The heights of these trees and their diameters (to the nearest 10 $\mathrm{cm}$ ) were estimated, while presence of first major branches (or scars from dropped branches) above or below half the trees' heights was recorded (following Torquebiau 1986). If, for example, most trees at a station branch above half-way to their crowns, then this suggests that these trees have grown up under a closed canopy (primary forest), while branching below half-way indicates recently disturbed forest, and the presence of scars suggests regenerating forest. Lack of time and manpower meant that estimation of habitat parameters was more practical than actually taking measurements. However, I had already four months' experience of taking such measurements and estimates, for example, of tree diameters, were periodically checked with a tape-measure to avoid drift in estimation. At each station, estimates were made of percentage covers at canopy, mid, low and ground levels within a $30 \mathrm{~m}$ radius. Gradient was estimated and presence of permanent water was recorded, within $50 \mathrm{~m}$ of the station. Altitude and distance from the station to the nearest village from where cockatoo trappers operate were recorded from maps.

All habitats surveyed were allocated to one of the following broad habitat groups: primary, disturbed primary, secondary and "young" selectively logged 
forests and "other". This last category included plantation, grassland, rank scrub and agricultural land. The disturbed primary forest category differs from secondary forest in that the former retains more of the structure characteristic of pristine forest (e.g. large trees branching above half their height and a more closed canopy). The logged forests surveyed had been logged "selectively" (see Johns 1988) between one and six years previously. On the walks between stations, no habitat data were taken, but the areas surveyed were allocated to the broad habitat groups as already described.

\section{Results}

On Seram, cockatoos were censused at 132 stations, and during 84.3 hours of walking in different habitats from sea level to approximately $1,800 \mathrm{~m}$. A total of 84 cockatoos were recorded and were seen singly or in "pairs" on 34 occasions, while groups of more than four birds were recorded three times (maximum group size was ten). Table I shows density estimates and encounter rates for $C$. moluccensis in broadly defined habitat types on Seram.

Table 1. Density estimates for C. moluccensis in different habitats on Seram, calculated from variable circular plots (Reynolds et al., 1980) using Buckland's "Distance" program, and encounter rates as proposed by Milton and Marhadi (1987)

\begin{tabular}{lcccr}
\hline & Density $\mathrm{km}^{-2}$ & Standard error km & $\begin{array}{c}\text { Encounter rate } \\
\text { per hr }\end{array}$ & $\begin{array}{c}\text { Time spent } \\
\text { in habitat hrs }\end{array}$ \\
\hline Primary & 9.1 & 6.3 & 1.0 & 8.3 \\
Disturbed primary & 9.8 & 7.7 & 2.5 & 10.8 \\
Secondary & 6.4 & 6.2 & 0.4 & 14.1 \\
Recently logged & 1.9 & 1.8 & 0.4 & 18.3 \\
Highland primary & 0.0 & & 0.0 & 7.9 \\
Other & 0.0 & & 0.0 & 25.1 \\
\hline
\end{tabular}

A Kruskal-Wallis one-way analysis of variance indicated that although withinhabitat variability in cockatoo enounter rates was high, there was a significant difference in encounter rates between habitats $\left(X^{2}=13.6, P<0.004\right)$. The results from the variable circular plot method suggest that while cockatoo densities were similar in primary and disturbed primary forests, densities seem to be lower in secondary forest, and much lower in recently logged forest. An advantage of the method used is that it takes into account the differences in detectability between habitats: the encounter rate method does not and this may explain why the two methods give rather different impressions of cockatoo distribution. The encounter rate method may exaggerate cockatoo abundance in more "open" habitats, as the birds may be more difficult to see in their preferred (at least according to the circular plot method) primary forest habitat.

Discriminant function analysis was used to account for the presence or absence of cockatoos at census stations by considering all the habitat and physical variables together. Variables estimated as percentages were converted to their arcsines and only records of cockatoos less than $100 \mathrm{~m}$ from stations were included. Table 2 shows the results of the analysis. 
Table 2. Relevant statistics from discriminant function analysis of the distribution of Salmon-crested Cockatoos on Seram. Variables were entered stepwise (Wilk's Method) and prior probabilities of group membership set at 0.5 .

\begin{tabular}{lr}
\hline Mean discriminant scores & \\
Stations without cockatoos & -0.12 \\
Stations with cockatoos & 1.28 \\
Standardized discriminant function coefficients \\
Diameter of largest tree & $\mathbf{1 . 1 6}$ \\
Average height of trees & $\mathbf{1 . 1 5}$ \\
Average tree girths & -0.83 \\
Distance to nearest village & -0.65 \\
Percentage cover at canopy level & -0.56 \\
Width of path & -0.53 \\
Number of regenerating trees & 0.44 \\
Time after o6h3o & 0.36
\end{tabular}

Pooled within-group correlations between variables and discriminant function (negative values for correlations appear in the right-hand column, i.e. high scores are associated with absence of cockatoos)

Associated with presence of cockatoos

\begin{tabular}{ll}
\hline Diameter of largest tree & 0.51 \\
Height of trees & 0.49 \\
Cover at low level & 0.28 \\
Average tree girths & 0.20 \\
No. of trees branching & \\
> halfway to crown & 0.19 \\
Cover at mid-level & 0.13 \\
Distance between trees & 0.12 \\
Time after o6h3o & 0.11 \\
Cover at ground level & 0.08 \\
Cover at canopy level & 0.07 \\
Number of dead trees & 0.03 \\
Classification results & \\
\multicolumn{1}{c}{ Actual group } &
\end{tabular}

Cockatoo absent Cockatoo present
Associated with absence of cockatoos

Discriminant function analysis is a multivariate technique which discriminates between two or more groups (in this case stations with and without cockatoos) by identifying characteristics shown by one group and not the other. The discriminant function coefficients are the weightings (degree of importance) of certain variables which best indicate whether cockatoos will be present or absent. Thus the best indicators of cockatoo presence (no causality is inferred) are the diameter of the largest tree and the average height of trees. While cockatoos tended to be recorded at stations with above-average values for these variables, they were also associated with open-canopied forests, since the coefficient for canopy cover is negative. The "discriminant function" is produced by the summation of the weightings (coefficients) of the indicating variables multiplied by the corresponding variable scores for each station. In the reclassifi- 
cation stage, each station is allocated to one of the two groups depending on its discriminant score. If the score is closer to 1.28 than -0.12 then cockatoos are predicted to be present. A "false positive" station is one which has the vegetation and physical characteristics of an "actual positive" station, yet cockatoos were not recorded there.

While the variables recorded had significant discriminating power to separate stations with cockatoos from those without cockatoos $\left(X^{2}=17.8, P=0.023\right)$, the discriminant model correctly predicted group memberships for only $76 \%$ of stations. However, the analysis predicts only that "positive" stations were in suitable habitat for cockatoos, not that cockatoos will always be present there.

Discriminant function analysis produces values which show to what degree each variable (separately) correlates with the overall "discriminating equation", and from these and the discriminant function coefficients a "profile" is developed for the species. The results suggest that cockatoos tended to be recorded in mature, open-canopied lowland forests with some very large, tall trees and some low vegetation. They also tended to be recorded more where paths were narrow, and the analysis suggests that cockatoos were weakly associated with areas closer to rather than farther away from settlements (the maximum distance of a station from a village was $19 \mathrm{~km}$ ).

\section{Discussion}

On Seram, cockatoos seem to be virtually absent above $1,000 \mathrm{~m}$ (which agrees with FAO 1981, Smiet 1985, Bowler and Taylor 1989) and rare or irregular in "other" habitats, and the species does seem to occur at higher densities in primary and disturbed primary forests than in other forests. The apparent differences in cockatoo densities between young logged forest and secondary forest is interesting, since many vegetation parameters (e.g. canopy covers and tree girths) were very similar in the two habitats (S. J. Marsden in prep.). Among the possible causes of this density difference are differential trapping pressures and patterns of disturbance, differences in tree species compositions and "gross" habitat heterogeneity, and differences in cockatoo densities in the respective areas before logging.

Bowler and Taylor's (1989) results from Seram in 1987, and Milton and Marhadi's (1987) study of the trade in White Cockatoos Cacatua alba on nearby Pulau Bacan, North Maluku, were extremely important, both in shaping opinion concerning the effects of the trade in Indonesian parrots, and in the decision by CITES to upgrade the Salmon-crested Cockatoo to Appendix I status. Milton and Marhadi (1987) did not calculate encounter rates for White Cockatoos in different habitats, although they concluded that $C$. alba did not appear to favour a particular habitat, but was widespread, occurring in gardens, plantations, secondary, primary, and recently logged forests. They did not, however, analyse any data from primary forests on that island.

Bowler and Taylor (1989) encountered C. moluccensis at 0.3 birds per hour in lowland rainforest around Solea and at 0.1 per hour at $600-900 \mathrm{~m}$ in the Manusela National Park enclave. Forest in the Manusela valley enclave has been heavily disturbed (FAO 1981), while the densities at which cockatoos occur at the upper end of their altitudinal range may be naturally low. Although it is 
difficult to relate Bowler and Taylor's "lowland rainforest" to the habitat classifications used in this paper, their figure for lowland forest around Solea suggests that cockatoos were rarer than in the lowland forest surveyed in this study.

The discriminant profile for $C$. moluccensis also suggests that cockatoos are dependent on little-disturbed lowland forest. Whether this "dependence" is a reflection of the species's specialized habitat requirements in terms of feeding and successful breeding, or whether it is a distribution dictated by the patterns and volume of bird capture, is as yet unclear. However, the lack of a negative correlation (it was positive) between the occurrence of cockatoos and the distribution of their captors is perhaps not a pattern to be expected from a species which has been systematically hunted towards extinction. If, however, some villages had been founded in areas of highly productive forest (for people and cockatoos), or if cockatoos have benefited from changes in vegetation around villages, then cockatoo numbers could still be higher in such areas, although nonetheless significantly depressed by high capture rates. What the analysis suggests is that cockatoos were no rarer close to habitation, even though (as interviews strongly indicated), it was usual for hunters to harvest cockatoos within only a few kilometres of their villages or camps. Perhaps most importantly, the results suggest that cockatoos are found at different densities in different land-use types, with more cockatoos being present where habitat alteration has occurred on a small scale. Most significant is that for each $100 \mathrm{~km}^{2}$ of Seram's primary forest that has been selectively logged in the last six years, there may have been a reduction in the population of $C$. moluccensis by around 700 birds. A similar conversion of locally disturbed secondary forest to, for example, plantation may have been characterized by the loss of around 600 birds.

While this short study offers only clues as to the relative importance of the concurrent effects of capture and habitat alteration on the population of the Salmon-crested Cockatoo, it indicates the clear need for a better understanding of the population dynamics of this and other Indonesian parrots. Further standardized fieldwork on Seram will yield more reliable data concerning cockatoo densities in, for example, other areas of the island, in older logged forest, and in mid-altitude habitats. By relating these data to information from the RePPProT mapping scheme, concerning present land types on Seram, and by using data on future land-use changes (e.g. logging concessions), it will be possible to model the changes in population of C. moluccensis in the coming years. From these data, and from information on the population dynamics of cockatoos (from Seram itself, from aviculturists, and from other regions, e.g. Australia), a long-term strategy for the conservation management of the Salmoncrested Cockatoo can be formulated.

\section{The Salmon-crested Cockatoo on Ambon}

Eight Salmon-crested Cockatoos and three unidentified cockatoos were observed during brief searches of remaining forest patches on Ambon. Local people stated that cockatoos were still present, but rare in other forested areas on that island. Although White and Bruce (1986) list C. moluccensis as of uncertain status on Ambon, the likelihood of large numbers of captive birds escaping (and not being re-caught) should be small. Most $C$. moluccensis free- 
flying on Ambon may well be wild birds, either resident and possibly breeding, or visiting birds from Seram, which is close to Ambon.

\section{Acknowledgements}

I thank Dr Martin Jones for organizing the Manchester Indonesian Islands Expedition and for supervising this project throughout. Dr Alan Fielding and Dr Colin Bibby very kindly helped with the analyses, and Dr Steven Buckland generously made available to us the "Distance" software for calculating bird densities. I am most grateful to Derek Holmes, Richard Grimmett, Tim Inskipp, John Bowler, Mike Hounsome and Roland Wirth for their great help during this project. Up-to-date information concerning the international trade in Salmon-crested Cockatoos was kindly supplied by the staff of the World Conservation Monitoring Centre. I appreciate the help of the staff of the Indonesian Directorate General of Forest and Species Protection (PHPA) and the hospitality of all those I met on Seram. The fieldwork was funded by an Oriental Bird Club Survey Grant.

\section{References}

Bowler, J. and Taylor, J. (1989) An annotated checklist of the birds of Manusela National Park, Seram. Kukila 4: 3-30.

Buckland, S. T. (1987) On the variable circular plot method of estimating animal density. Biometrics 43: $363-384$.

Food and Agriculture Organization (FAO) (1981) Proposed Manusela National Park Management Plan 1982-1987. UNDP/FAO FO/INS/78/061 Field Report 15.

Forshaw, J. M. (1989) Parrots of the world. Third edition. Poole: Blandford.

Inskipp, T., Broad, S. and Luxmoore, R. (1988) Significant trade in wildlife: a review of selected species in CITES Appendix 2. Vol 3: Birds. Cambridge, U.K.: CITES/IUCN.

Johns, A. D. (1988) Effects of "selective" timber extraction on rain forest structure and composition and some consequences for frugivores and foliovores. Biotropica 20: 31-37.

Milton, G. R. and Marhadi, A. (1987) An investigation of parrots and their trade on Pulau Bacan (North Moluccas) and Pulau Warmer, Aru Islands. WWF/IUCN, unpublished.

Reynolds, R. T., Scott, J. M. and Nussbaum, R. A. (1980) A variable circular plot method for estimating bird numbers. Condor 82: 309-313.

Smiet, F. (1982) Threats to the Spice Islands. Oryx 16: 323-328.

Smiet, F. (1985) Notes on the field status and trade of Moluccan parrots. Biol. Conserv. 34: 181-194.

Stresemann, E. (1914) Die Vögel von Seram. Novit. Zool. 21.

Torquebiau, E. F. (1986) Mosaic patterns in Dipterocarp rain forest in Indonesia and their implications for practical forestry. J. Trop. Ecol. 2: 301-325.

White, C. M. N. and Bruce, M. D. (1986) The birds of Wallacea. London: British Ornithologists' Union.

\section{STUART J. MARSDEN}

Conservation Research Group, Department of Biological Sciences, Manchester Polytechnic, Manchester MI 5GD, U.K. 